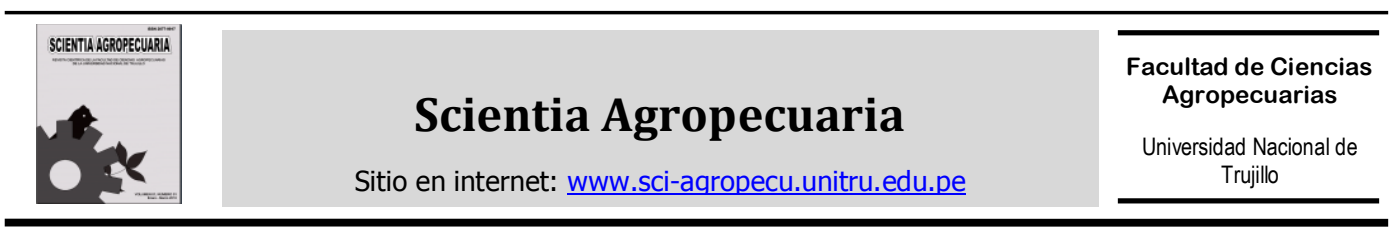

Influencia del caudal de aire, temperatura y velocidad de agitación en el proceso discontinuo de acetificación para la obtención de vinagre de naranja (Citrus sinensis var.W. Navel)

\title{
Influence of air flow, temperature and agitation speed in the batch acetification process to obtain orange vinegar (Citrus sinensis var.W. Navel)
}

\author{
María Ferreyra*; María Schvab; Cristina Davies; Liliana Gerard; Roque Hours \\ Facultad de Ciencias de la Alimentación. Universidad Nacional de Entre Ríos. Monseñor Tavella 1450 (3200). Concordia. \\ Entre Ríos. Argentina
}

Recibido 04 diciembre 2011; aceptado 29 marzo 2012

\begin{abstract}
Resumen
Se describe la influencia de variables de proceso para la producción de vinagre de naranja. El jugo de naranja, se fermentó con Saccharomyces cerevisiae hasta $14 \%$ v/v de alcohol. La bioxidación se realizó con Acetobacter sp., en cultivo sumergido, en biorreactor de laboratorio. Para evitar el efecto inhibidor del etanol sobre las bacterias acéticas, el vino de naranja fue diluido a $6 \% \mathrm{v} / \mathrm{v}$ de alcohol con solución de minerales. La influencia de las variables se evaluó con diseño factorial $2^{\mathrm{k}}$. Se estudió caudal de aire/velocidad de agitación, ensayando los niveles 0.3 - $0.6 \mathrm{vvm}$ y 200 - $400 \mathrm{rpm}$ y luego, caudal de aire/temperatura, siendo los niveles para cada variable $0.4-0.6 \mathrm{vvm}$ y $25-30{ }^{\circ} \mathrm{C}$, respectivamente. Cada tratamiento se realizó por duplicado, usando como respuestas productividad y rendimiento. El análisis del diseño $(\alpha<0.05)$ se efectuó mediante programa Statgraphics Centurion XV Corporate. En los tratamientos con $200 \mathrm{rpm}$ y distintos caudales de aire, no hubo diferencias significativas respecto a la productividad. A mayor velocidad de agitación y caudal de aire, la productividad fue mayor. Los mayores rendimientos se obtuvieron con menores caudales de aire y mayores velocidades de agitación. Con respecto a la temperatura, los valores ensayados no presentaron diferencias significativas en las respuestas estudiadas. El mejor rendimiento se obtuvo con $400 \mathrm{rpm}$ y $0.3 \mathrm{vvm}$ a $25{ }^{\circ} \mathrm{C}$. Se concluye que la velocidad de agitación juega un rol muy importante para lograr una mejor productividad mientras que elevados flujos de aire disminuyen el rendimiento.
\end{abstract}

Palabras clave: vinagre de naranja, caudal de aire, velocidad de agitación, temperatura.

\begin{abstract}
This paper describes the influence of process variables to produce orange vinegar. Orange juice was fermented with Saccharomyces cerevisiae until reach $14 \%$ v/v. The biooxidation was carried out with Acetobacter sp., in submerge culture using a laboratory scale fermentor. In order to avoid the inhibitory effect of ethanol on acetic acid bacteria, the orange wine was diluted to $6 \% \mathrm{v} / \mathrm{v}$ with a mineral solution. It was performed a factorial design $2^{\mathrm{k}}$ to study the influence of variables. It was studied air flow rate/agitation at levels of 0.3-0.6 vvm and 200-400 rpm and the effect of air flow rate/temperature at 0.4-0.6 vvm and 25$30^{\circ} \mathrm{C}$, respectively. Duplicate treatments were carried out and the results were evaluated in terms of productivity and fermentation yield. Statistical design ( $\mathrm{p}$-value $<0.05$ ) was analyzed using Statgraphics Centurion XV Corporate software. Treatments performed at $200 \mathrm{rpm}$ and different air flow levels, did not show significant differences on acetification rate. At higher agitation speed and air flow rates, the productivity was high. The best yields were obtained at lower air flows levels and higher agitation speed. Temperature did not present statistically differences on studied variables. The best yield was obtained at $400 \mathrm{rpm}$ and $0.3 \mathrm{vvm}$ at $25^{\circ} \mathrm{C}$. It can be concluded that agitation speed plays an important role for a better acetification rate however higher air flow rates causes less yields.
\end{abstract}

Keywords: orange vinegar, air flow rate, agitation speed, temperature.

\footnotetext{
* Autor para correspondencia

Email: ferreyram@fcal.uner.edu.ar (M. Ferreyra)
} 


\section{Introducción}

La producción citrícola de Argentina está destinada básicamente al mercado de fruta fresca (FEDERCITRUS, 2009).No existen productos derivados de la transformación de los jugos cítricos, que incrementen su valor agregado. Las bebidas alcohólicas y los vinagres constituyen alternativas tecnológicas para la obtención de productos novedosos.

Se definen dos métodos para la producción de vinagre: el tradicional (lento) y el sumergido (rápido).

En el primer caso, las bacterias acéticas se desarrollan en la superficie, en contacto directo con el $\mathrm{O}_{2}$ atmosférico. Se lo emplea en la producción de vinagres selectos. (Tesfaye et al., 2002).

En el sistema de cultivo sumergido las bacterias acéticas están suspendidas en el liquido al cual se le aplica aireación de acuerdo a la demanda de oxigeno. De acuerdo a Nieto et al. (1993) el valor mínimo es $0.4-0.5$ ppm. Es la tecnología más usada en la industria con diversas modificaciones en las condiciones de fermentación, tales como aireación, agitación, control de temperatura, etc. (de Ory et al., 2004).

Los principales factores del proceso son: sustrato, oxígeno y temperatura (Tesfaye $e t$ al., 2003).

La aireación adecuada no incrementa las concentraciones de $\mathrm{O}_{2}$ durante la fase estacionaria del proceso pero aumenta la población bacteriana y la velocidad de acetificación. Un excesivo suministro de aire puede afectar la composición volátil del medio y producir una disminución de la calidad y rendimiento del producto (Romero y Cantero, 1998).

La temperatura ideal está comprendida entre 28 y $30^{\circ} \mathrm{C}$. Esta variable influye en el rendimiento global, debido a la evaporación de los volátiles, tales como etanol, acetaldehído y ácido acético (Romero y Cantero, 1998).

El objetivo del presente trabajo fue evaluar la influencia de la velocidad de agitación, caudal de aire y temperatura durante la acetificación de vino de naranja en proceso discontinuo, sobre el rendimiento y la velocidad de acetificación.

\section{Material y métodos}

\section{Fermentación alcohólica}

El vino de naranja var. W. Navel, sustrato de la fermentación acética se obtuvo con una $S$. cerevisiae autóctona, aislada en nuestro laboratorio a partir de naranjas de la zona, la cual demostró adecuadas características enológicas (Ferreyra, 2006). Se realizó la fermentación alcohólica del mosto ajustando el $\mathrm{pH}$ a 3,5, e incubando en anaerobiosis a $20^{\circ} \mathrm{C}$. En el vino joven se determinaron: $\mathrm{pH}$, graduación alcohólica (\% v/v) y acidez volátil: (\% de ácido acético anhidro). Se usaron técnicas de la AOAC (1995).

\section{Acetificación}

Se realizó en cultivo sumergido, en un biorreactor New Brünswick Cientific Co., Bioflo 2000, con accesorios para control de variables. Para evitar el efecto inhibidor del etanol sobre las bacterias acéticas, el vino fue diluido hasta un $6 \% \mathrm{v} / \mathrm{v}$ de alcohol. Se inoculó con Acetobacter sp. Se monitorearon: el $\mathrm{pH}$, acidez volátil $(\mathrm{g} / \mathrm{L}$ $\mathrm{AcH}), \mathrm{DO}_{\kappa=540} \mathrm{y}$ la concentración de etanol $(\% \mathrm{v} / \mathrm{v})$. El proceso se continuó hasta que la concentración de ácido acético, se estabilizó en el orden de $60 \mathrm{~g} / \mathrm{L}$.

Se analizaron los resultados aplicando un diseño factorial completo del tipo $2^{\mathrm{k}} \mathrm{y}$ ANOVA $(\alpha=0.05)$, con programa Statgraphics Centurion XV Corporate. Las variables independientes estudiadas fueron: caudal de aire, velocidad de agitación y temperatura y las respuestas (variables dependientes), velocidad de acetificación o productividad, $p$ (ecuación 1) y rendimiento, $R$ (ecuación 2 ).

$$
p=\frac{C_{A 2}-C_{A 1}}{t_{2}-t_{1}} \quad \text { Ec. } 1
$$

Donde $\mathrm{C}_{\mathrm{A} 1}$ y $\mathrm{C}_{\mathrm{A} 2}=$ concentración de ácido acético ( $\mathrm{g} \mathrm{AcH} / \mathrm{L}$ ) para los tiempos $\mathrm{t}_{1} \mathrm{y} \mathrm{t}_{2}$, respectivamente (Nieto, 1991; Tesfaye et. al., 2000). 
$R=\frac{\text { Conc. } \text { Total del Vinagre }}{\text { Conc. Total del Vino }} \times 100$

Ec. 2

Las condiciones iniciales del sustrato, fueron: $\mathrm{pH}$ : 3.4, volumen: $2 \mathrm{~L}$, etanol: $6 \%$ v/v y ácido acético: 6.6 g/L.

\section{Resultados y discusión}

Las características fisicoquímicas del vino base fueron: graduación alcohólica: $14 \%$ v/v; acidez volátil: $1.75 \mathrm{~g} \mathrm{AcH} / \mathrm{L} ; \mathrm{pH}=$ 3.9. La fermentación acética fue conducida por Acetobacter sp., cuya primera actividad es su desarrollo poblacional hasta alcanzar el número de células necesarias para constituir el cultivo iniciador del proceso. Las bacterias acéticas pueden oxidar etanol aún a concentraciones de $\mathrm{O}_{2}$ tan bajas como 0.4 ó 0.5 ppm pero no se pueden multiplicar en estas condiciones (Nieto et al., 1993).

Del seguimiento del proceso a través de la medida de la $\mathrm{DO}_{\lambda=540}$ y de la acidez, se pudo observar que la fase log se prolongó más allá de las $20 \mathrm{~h}$ de proceso. En la Figura 1 se muestra este comportamiento para un caudal de aire de $0.6 \mathrm{vvm}$, una agitación de $400 \mathrm{rpm}$ y $25^{\circ} \mathrm{C}$. Además se pone de manifiesto que tanto el crecimiento como la producción de ácido acético tienen un comportamiento similar durante el desarrollo de dicha fase. Sin embargo, mientras la acidez sigue aumentando el crecimiento se ve retardado hasta hacerse estacionario.

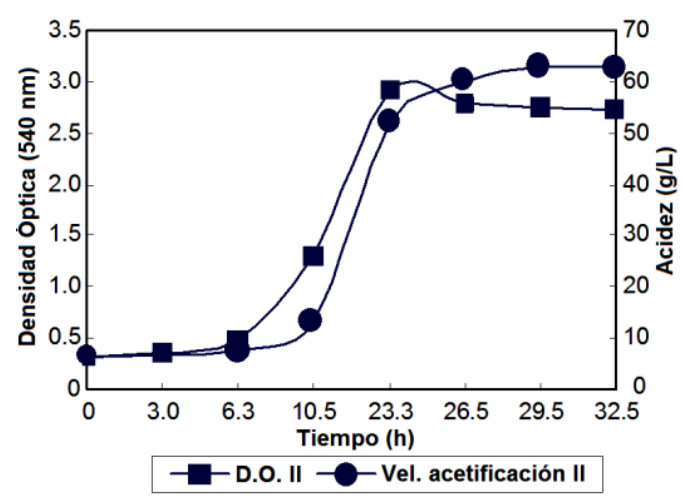

Figura 1. Relación entre el crecimiento microbiano y la producción de ácido acético.
El estudio de la fermentación acética es complicado debido a la gran interdependencia existente entre todas las variables intervinientes. Ninguna observación es válida si no se detallan las condiciones bajo las que se ha realizado, ya que el efecto de una variable de proceso depende mucho de la situación de las demás (Nieto, 1991).

Una de las técnicas más eficientes para el análisis de los procesos es la aplicación de un diseño estadístico experimental. Esta metodología permite determinar la influencia e importancia de los parámetros estudiados y las interacciones entre estos con un mínimo de ensayos.

A los efectos de analizar rendimiento y productividad frente a las variables, temperatura $\left(25^{\circ} \mathrm{C} \mathrm{y} 30^{\circ} \mathrm{C}\right)$, caudal de aire (0.3 vvm y 0.6 vvm) y velocidad de agitación (200rpm y 400 rpm) se aplicó un diseño experimental estadístico del tipo factorial equilibrado $2 \mathrm{k}$.

En la Tabla 1 se muestra la matriz de diseño y las respuestas. Para cada una se realizo el ensayo de ANOVA con un nivel de confianza del $95 \%$.

\section{Tabla 1}

Matriz del diseño experimental.

\begin{tabular}{rcccc}
\hline $\begin{array}{r}\text { Caudal } \\
\text { de Aire } \\
(\text { vvm })\end{array}$ & $\begin{array}{c}\text { Veloc de } \\
\text { Agitación } \\
(\mathrm{rpm})\end{array}$ & $\begin{array}{c}\text { Temp. } \\
\left({ }^{\circ} \mathrm{C}\right)\end{array}$ & $\begin{array}{c}\text { Veloc. } \\
\text { Acetif. } \\
(\mathrm{g} / \mathrm{Lh})\end{array}$ & $\begin{array}{c}\text { Rend. } \\
(\%)\end{array}$ \\
\hline$-1(0.3)$ & $1(400)$ & $1(30)$ & 1.00 & 75.80 \\
$1(0.6)$ & $-1(200)$ & $1(30)$ & 0.30 & 49.80 \\
$-1(0.3)$ & $-1(200)$ & $-1(25)$ & 0.18 & 60.80 \\
$1(0.6)$ & $-1(200)$ & $-1(25)$ & 0.30 & 46.80 \\
$-1(0.3)$ & $-1(200)$ & $1(30)$ & 0.20 & 60.30 \\
$1(0.6)$ & $1(400)$ & $-1(25)$ & 1.77 & 92.12 \\
$-1(0.3)$ & $1(400)$ & $-1(25)$ & 1.76 & 94.07 \\
$1(0.6)$ & $1(400)$ & $1(30)$ & 1.30 & 75.70 \\
\hline (): Valores reales & & &
\end{tabular}

En la Figura 2 se muestra el efecto de las variables y sus interacciones. En este caso la respuesta considerada fue la velocidad de acetificación. El estadístico $\mathrm{R}^{2}$ indica que el modelo ajustado explica el $99.64 \%$ de su variabilidad.

En el diagrama de Pareto se observa que el efecto más importante con signo positivo se debe a la velocidad de 
agitación. De las otras variables principales, la temperatura tiene signo negativo y el caudal de aire positivo, pero ambos sin significancia estadística $(\alpha=0.05)$.

En condiciones de operación típicas de los fermentadores, un aumento en la velocidad del agitador mejora el valor del coeficiente volumétrico de transferencia de materia $\left(\mathrm{k}_{\mathrm{L}} \mathrm{a}\right)$, mientras que un aumento en el caudal de aire produce generalmente un efecto muy pequeño sobre $\left(\mathrm{k}_{\mathrm{L}} \mathrm{a}\right)$ (Doran, 1998). Es posible que esto último haya ocurrido en los tratamiento comparados: si el $\mathrm{k}_{\mathrm{L}} \mathrm{a}$ no se modifica sustancialmente, la velocidad de transferencia de oxígeno al medio no varía mucho, y no se logran poblaciones bacterianas más elevadas, con lo que la velocidad de conversión de vino en vinagre tampoco varía (Nieto, 1991). Probablemente el tamaño de la burbuja logrado con $200 \mathrm{rpm}$ no haya sido lo suficientemente pequeño como para lograr una buena transferencia de materia.

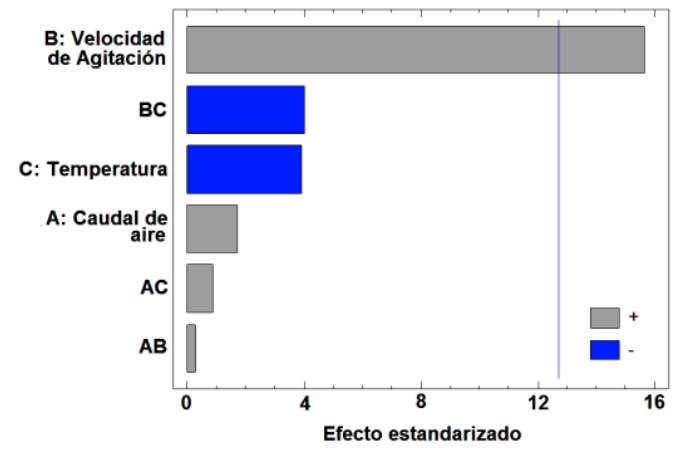

Figura 2. Diagrama de Pareto para la velocidad de acetificación.

A $400 \mathrm{rpm}$, podría pensarse que el aumento de la velocidad de conversión de alcohol en ácido acético, fue favorecido por el incremento de esta variable, El tiempo total del proceso disminuyó desde 150 a $36 \mathrm{~h}$ cuando la velocidad de agitación pasó de 200 a 400 rpm.

La productividad aumentó al descender la temperatura. A $25^{\circ} \mathrm{C}$ y $400 \mathrm{rpm}$, fue de $1.77 \mathrm{~g} / \mathrm{Lh}$ mientras que a $30^{\circ} \mathrm{C}$ e igual velocidad de agitación fue de $1.0 \mathrm{~g} / \mathrm{Lh}$, resultados con igual tendencia a los obtenidos por de Ory et al. (1998).
Cuando la respuesta estudiada fue el rendimiento también la variable de mayor peso resultó ser la velocidad de agitación tal como se puede observar en la Figura 3. El estadístico $\mathrm{R}^{2,}$ arrojó un valor de $99.82 \%$.

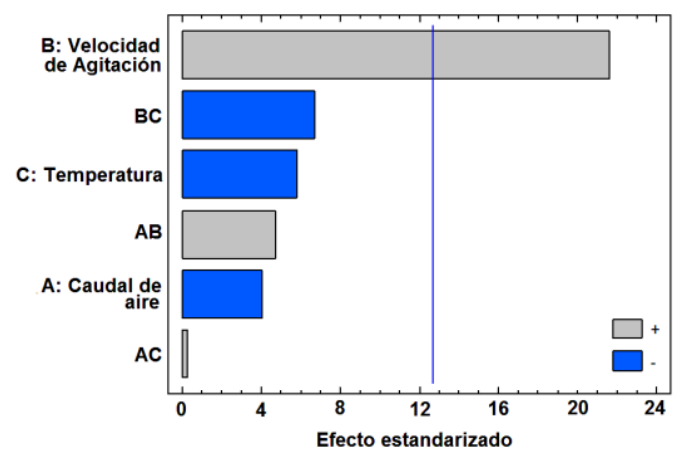

Figura 3. Diagrama de Pareto para el rendimiento.

La evaporación de los volátiles durante la fermentación acética es una de las mayores causas de reducción en el rendimiento. En los sistemas discontinuos es necesario suministrar una cantidad considerable de aire aumentando las pérdidas por evaporación. A bajos caudales de aire, los rendimientos aumentan y disminuyen las pérdidas por evaporación. (RubioFernandez et al., 2000). En el presente trabajo el mayor rendimiento fue el que se obtuvo a $25^{\circ} \mathrm{C}, 0.3 \mathrm{vvm}$ y $400 \mathrm{rpm}$.

Si bien la aireación es muy importante en los procesos aeróbicos, la agitación es necesaria por varias razones que podrían sintetizarse como el aumento en las velocidades de transferencias involucradas en el proceso, pero además la generación de la turbulencia de la agitación mejora la aireación, al dispersar el aire en pequeñas burbujas y disminuir el ancho de la película de la interfase gas- líquido. En este caso el rendimiento se vio favorecido cuando se trabajó con la mayor velocidad de agitación. Si bien para las dos respuestas estudiadas la interacción entre la temperatura y la velocidad de agitación no tiene significancia estadística es interesante tenerlo en cuenta para minimizar las pérdidas por evaporación de sustrato y productos. 


\section{Conclusiones}

En el presente trabajo el mayor rendimiento fue el que se obtuvo a $25^{\circ} \mathrm{C}, 0.3$ vvm y $400 \mathrm{rpm}$. Se puede determinar que podrían emplearse mayores velocidades de agitación de manera de aumentar tanto la velocidad de acetificación como el rendimiento, manteniendo la temperatura al nivel mínimo aceptable para el proceso a los fines de minimizar las pérdidas por evaporación.

\section{Referencias bibliográficas}

AOAC, 1995. Association of Official Analytical Chemists. Official Methods of Analysis. ed. Arlington.

de Ory, I.; Romero, L.E.; Cantero, D. 1998. Modelling the kinetics of growth of Acetobacter aceti in discontinuous cultura: influence of the temperature of operation. Applied Microbiology Biotechnology 49: 189-193.

de Ory, I.; Romero, L.E.; Cantero, D. 2004. Operation in semi-continuous with a closed pilot plant scale acetifier for vinegar production. Journal of Food Engineering 63: 39-45.

Doran, P.M. 1998. Principios de ingeniería de los bioprocesos. Editorial Acribia S.A. Zaragoza, España

FEDERCITRUS, 2009. Federación Argentina del Citrus. La Actividad Citrícola Argentina 2009. Disponible en: http://www.federcitrus.org/actividad-citricola-2009.pdf
Ferreyra, M. 2006. Estudio del proceso biotecnológico para la elaboración de una bebida alcohólica a partir de jugo de naranjas. Tesis Doctoral. Universitat Politècnica de València (España).

Nieto, F.J. 1991. Algunos aspectos de la tecnología de la fermentación acética. En: El vinagre de vino. Llaguno, C., Polo, M.C. eds. Madrid, España., CSIC, 69-103.

Nieto, F.J., Gonzalez-Viñas, M.A. Barba, P.; MartinAlvarez, P.J.; Aldave, L.; Garcia-Romero, E.; Cabezudo, M.D. 1993. Resent progress in wine vinegar R \& D and some indicators for the future. En Food Flavor, Ingredients and Composition 469 - 499. Ed. por G. Charalambous. Elsevier Science Publishers B.V., clave: CL.

Romero, L.E.; Cantero, D. 1998. Evaluation of etanol evaporation losses in acetic acid fermentations. Bioprocess Engineering 18: 289 - 291.

Rubio-Fernandez, H.; Salvador, M. D.; Fregapane, G. 2000 Contribución a la mejora del proceso de acetificación para la producción industrial de vinagre de vino. Alimentación, equipos y tecnología 19(1): 209 - 214.

Tesfaye, W.; García-Parrilla, M.C.; Troncoso, A.M. 2000. Set up and optimization of laboratory scale fermentor for the elaboration of wine vinegar. Journal of the Institute of Brewing 106(4): 215-219.

Tesfaye, W.; Morales, M.L.; García-Parrilla, M.C.; Troncoso, A.M. 2003. Optimising wine vinegar production: fermentation and ageing. Applied Biotechnology. Food Science and Policy 1(2): 109114

Tesfaye, W.; Morales, M.L.; García-Parrilla, M.C. ; Troncoso, A.M. 2002. Wine Vinegar: technology, authenticity and quality evaluation. Trends in Food Science and Technology 13: 12-21. 